\title{
Affective Educational Application of Fish Tank Hydroponics System
}

\author{
Rodolfo Romero Herrera ${ }^{1}$ \\ Departamento de Ciencias e Ingeniería de la Computación \\ Instituto Politécnico Nacional-ESIME-ESCOM \\ Ciudad de México, México
}

\author{
Francisco Gallegos Funes $^{2}$ \\ Sección de Estudios de Posgrado e Investigación \\ Instituto Politécnico Nacional- ESIME \\ Mexico
}

\begin{abstract}
This project develops algorithms for the design and implementation of an embedded system in hydroponic gardens for homes located on roofs, terraces, and even in kitchens in the house; since a fishbowl is used. Vegetables, flowers, etc. are contemplated. One plant was obtained per seed. The development and care of Nature is also a special theme of this project with the objective of educating in the care of the environment, for which it is essential not to overlook the affection that one has for life. It is here that it is important to ensure that plants can transmit the physical conditions in which they find themselves through an emotional interface that translates the lack of water into an emotional state of sadness; or enough moisture with a state of joy. Thus a technique is presented, which allows through affective or emotional interfaces to educate owners about the care of the plant and take advantage of the emotional states of the people for the development of educational software.
\end{abstract}

Keywords-Hydroponics; affective interface; embedded system; gardens; educational software

\section{INTRODUCTION}

The inhabitants of the cities live in houses with small gardens, patios and/or balconies. Thus, keeping plants alive is complicated. Vegetation requires care; and in most cases, there are no educational tools to guide the owner [1], and much less equipment is available for plants to communicate with us.

The educational material developed is a consequence of the reflection of the impact of plants on our planet [2]. Currently, there are government programs for the care of the environment [3]; such as those based on indigenous knowledge or those promoted by the Government Commissions [4].

There are several educational proposals [5], such as those that develop interactive software tools with touch screens [2]; and in urban environments, there are school gardens, which require the development of materials for students [6]; and virtual models allow simulating the cultivation of fruit trees [7]; In addition, there are websites that contain information about plant care [8]; however, there is still a shortage of applications that bring the person to consider their plants as part of the family. Many people in the home take great care of their pets; So why not consider your plants with equal attention. After all, they provide us with several benefits.

Because most housewives or end-users lack knowledge and interest in plant care, it is proposed to develop a system that considers both hardware and software development that facilitates the approach to raise awareness about the protection of nature. For this, it is proposed to use the affection that a user feels for what is his property, in this case, the plants.

\section{OBJeCTIVES}

\section{A. General}

Develop a system that translates the physical conditions of a plant into a simulation of affective states using advanced technologies in a hydroponics fish tank and educational software.

Thus, happiness is interpreted as sufficient humidity; and sadness like dry land or low humidity. Also, the ambient temperature is related to reflect anger and the level of ph with fear.

\section{B. Specific}

- Development of affective interface module through images that reflect moods depending on humidity, temperature and $\mathrm{pH}$ sensor readings.

- Development of a learning tool for plant care with recommendations and indications ranging from germination to harvest or flowering.

- Development of a system for sensing plant conditions.

\section{Methodology AND DEVElopment}

Plants need 16 elements, 9 macronutrients that must be provided in greater quantities (Hydrogen, Carbon, Oxygen, Nitrogen, Calcium, Phosphorus, Magnesium, Potassium and Sulfur) and 7 micronutrients (Chlorine, Zinc, Boron, Iron, Copper, Manganese, Molybdenum) that are required in smaller proportions [9]. Oxygen and $\mathrm{CO} 2$ are obtained from the environment; Hydrogen and oxygen are obtained from water. In the case of hydroponics, macronutrients and micronutrients dissolve in water (nutrient solution).

Fish hydroponics was chosen, as it is economical and easily accessible for the home. The main advantages of the system are control, efficient water consumption and full use of the substrate.

\section{A. Hydroponics}

Hydroponics is used to grow plants where soil use is not necessary [10]. The proposed hydroponic system does not consider traditional NFT [11]. But use a circulating nutrient solution (see Fig. 1). 


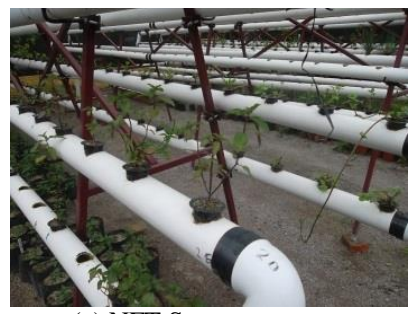

(a) NFT System.

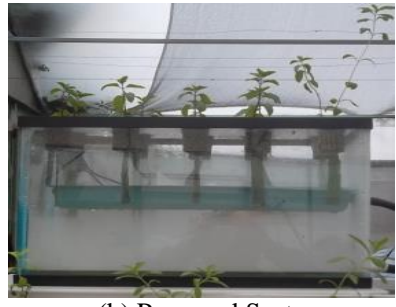

(b) Proposed System.
Fig. 1. Hydroponic Systems.

The realized system has automatic irrigation. Hydroponics requires maintaining a water level; so a liquid level sensor is used. Materials such as cotton or some fiber absorb liquid and nutrients (see Fig. 2). For hot days a water spray system was implemented; When a certain level of aridity is reached, an electronic key is opened for water to flow and the spray pump is activated; the water pumping system closes when there is a certain level of temperature and humidity [12]. For cold days there is a fish tank heater.

To avoid the nutrient solution plate on the water surface, a pump was used to recycle the fish tank liquid (see Fig. 3).

\section{B. Algorithms - Agent for Automation}

The system is controlled by an Arduino Uno card, which obtains sensible information, that activates the corresponding actuators [13]; the result is transmitted wirelessly via WiFi to a cell phone, tablet or PC. Thresholds are used to determine simulated emotions. The data are taken from the sensors and can be adjusted (see Fig. 4).
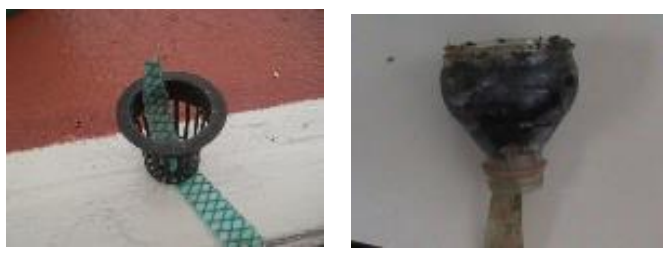

Fig. 2. Spray System.

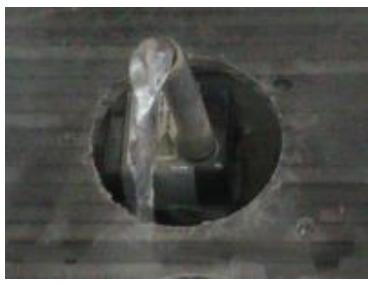

Fig. 3. Pumping System.

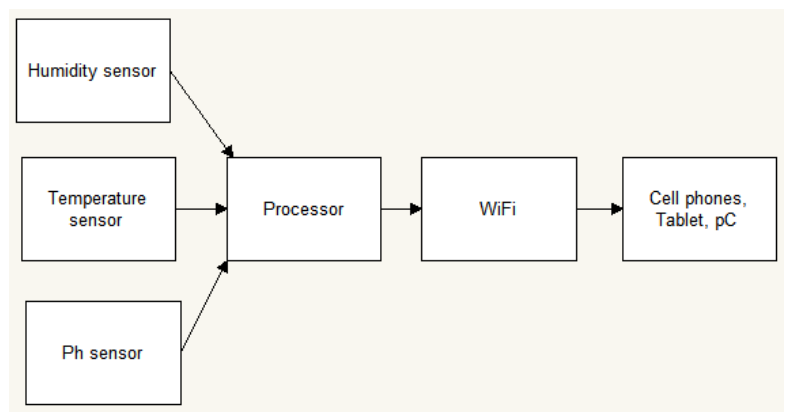

Fig. 4. Sensing Process.

\section{Sensing Humidity and Water Level}

To detect the water level, a soil moisture sensor (hygrometer FC28) was used. If there is greater humidity the conductivity increases and if the soil is very dry the conductivity decreases. A card (comparator LM393) was added for sensing analogously or digitally [14]. The zero value corresponds to soil with high conductivity and the 1023 value to practically dry soil. The digital output delivers the value "HIGH" when the humidity threshold is exceeded and LOW when it is below, this level can be modified through the potentiometer (see Fig. 5).

If analog signal $\mathrm{A} 0$ is used, the value is read; and the serial port is used to transmit information to a computer (see Fig. 6).

\section{Temperature Sensing Agent}

An RTD (resistance temperature detector) is a resistive temperature sensor; it is based on the variation of the resistance of a conductor that is proportional to the increase or decrease in temperature [15]. The LM35 was used (see Fig. 7). You can calculate the temperature based on the voltage with equation (1) and use the diagram in Fig. 8 for the program.

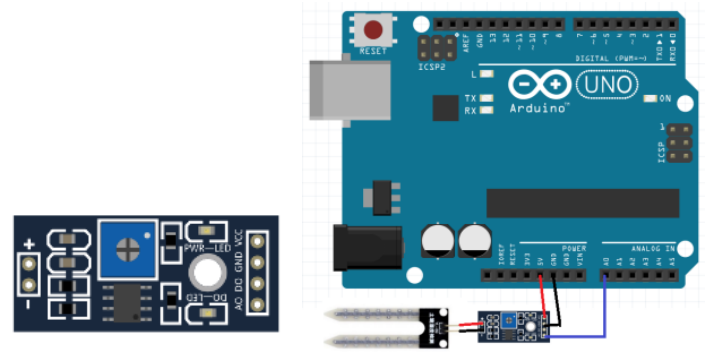

Fig. 5. Mounting the Humidity and Liquid Level Sensing System.

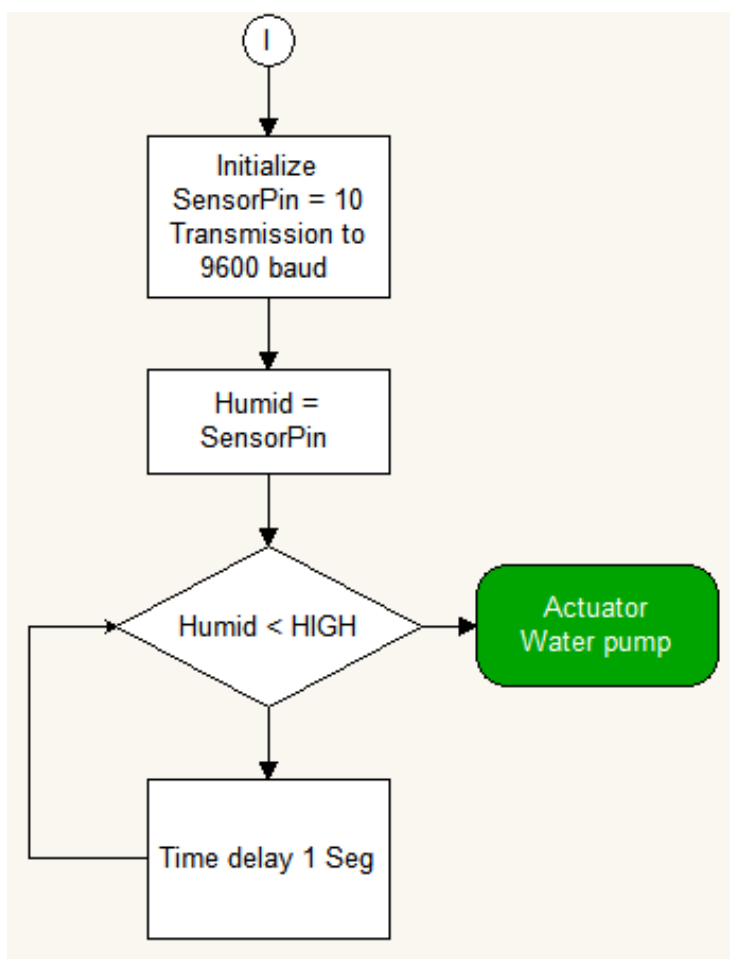

Fig. 6. Flow Diagram of the Humidity Sensing by a Digital Input. 


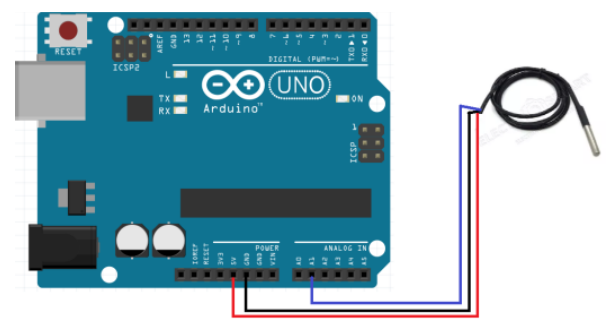

Fig. 7. Temperature Sensor.

To set the analog reference, an Arduino one function is used, which sets the reference for the entry with a value of 1023. If the INTERNAL option is used, $1.1 \mathrm{v}$ can be used for higher resolution.

Temperature $=$ Value $* 1.1 * 100 / 1024$

The code that we must load corresponds to the flowchart of Fig. 8.

\section{E. Ambient Light Sensor Agent}

Artificial lighting was used in the case of closed environments. The LED strips are automatically turned on by time and by lumens in the room (see Fig. 9).

The TEMT6000 sensor is sensitive to the visible spectrum. The output of this sensor is analog, so it connects to the Arduino ADC. In this case, the ambient light is the measured variable; When the module does not detect enough light, a signal is emitted to the Arduino to turn on the LED strip; otherwise, if the light is sufficiently intense, the Arduino is instructed to turn off the LED strip (see Fig. 10).

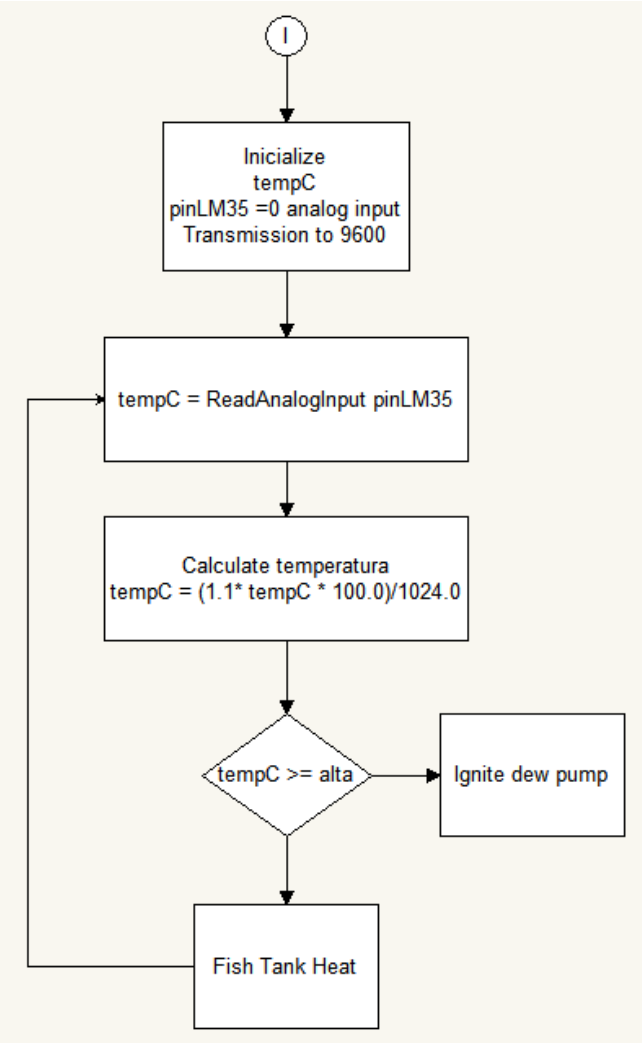

Fig. 8. Flow Chart of Temperature Sensing with the INTERNAL Option.

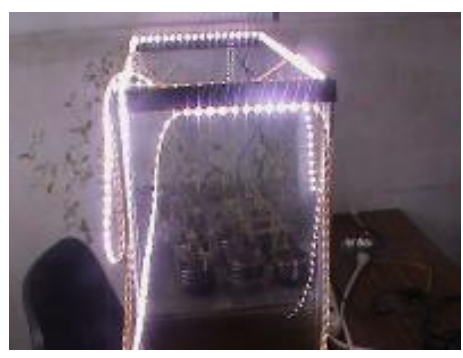

Fig. 9. Lighting System.

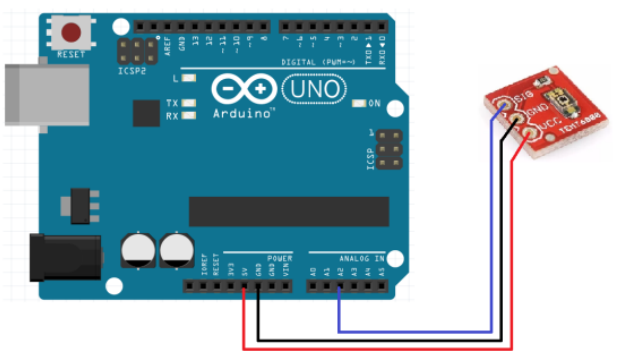

Fig. 10. Mounting the Ambient Light Sensing System.

In the diagram of Fig. 11, first are assigned the input and output ports on the microcontroller and the ranges that were used for the variable "sunlight" (this is adjustable). It is set to 0 for the sensor to send the signal to turn off the microcontroller once it detects light. When the sensor does not register enough light in the room, it will send the signal to the microcontroller to turn on the LED strip.

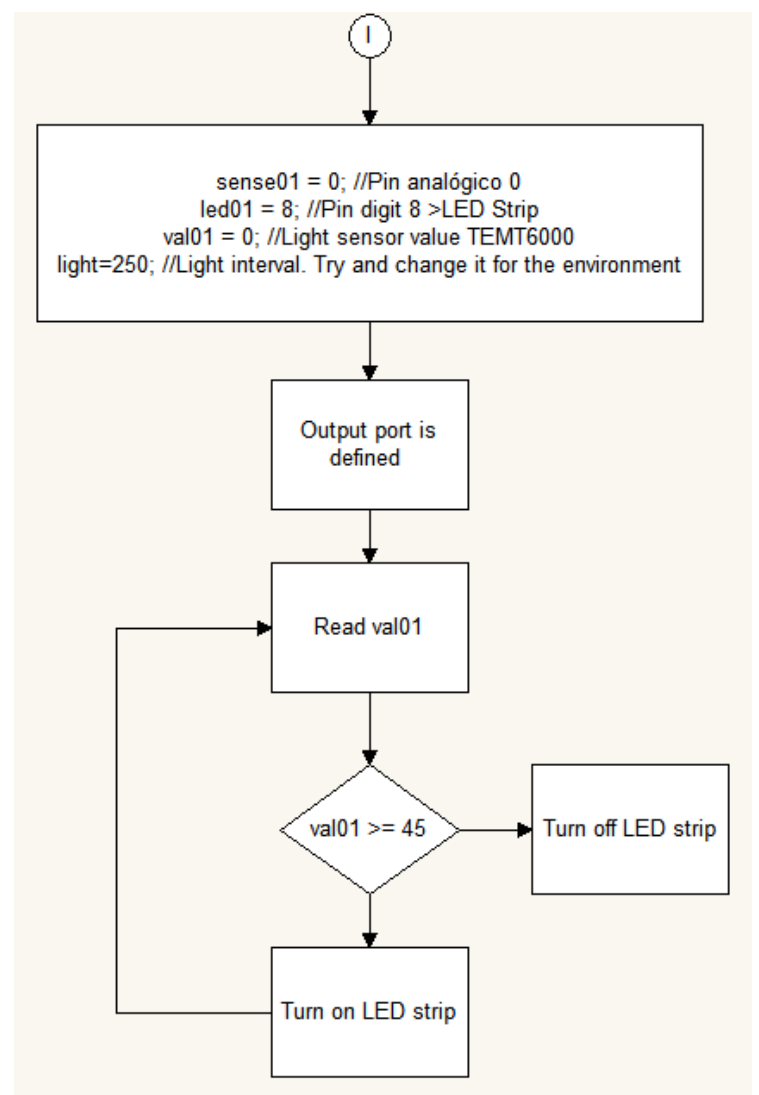

Fig. 11. Flow Chart - LED Strip Ignition. 


\section{F. ESP8266 Wifi Transmission}

Wireless communication through Wi-Fi to a cell phone or PC was chosen (see Fig. 12). The ESP8266 was used with the microcontroller as an Arduino connected to its serial port and managed with Hayes commands [4]. The connection diagram is shown in Fig. 12. The ESP8266 is a Wi-Fi chip with a TCP / IP stack and an MCU (Micro Controller Unit).

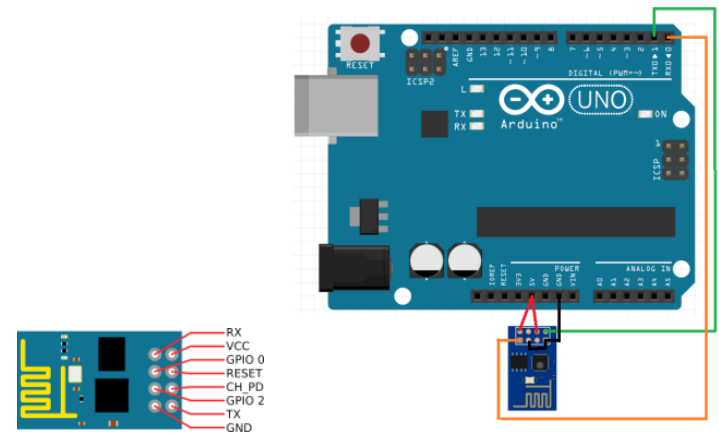

Fig. 12. Connection Diagram.

\section{EDUCATIONAL INTERFACE FOR PLANTS CARE}

To design the software, we proceeded under the methodology proposed by Becerra and Torres in [2]. An initial inquiry was made with general aspects to identify the main problems in plant cultivation. In the second stage, the Educational didactic model was selected with a teachinglearning approach; in order to make people aware of their responsibility in the care of nature. In the third stage, The contents of the module were structured with information on each of the main problems during planting. germination, growth care, harvesting, and pruning. See Fig. 13.

For the design of the didactic model, a proposal was taken as in reference [8] in 10 points:

1) The genesis of the idea.

2) Pre-design or functional design.

3) Feasibility study and project framework.

4) Design report and project framework.

5) Programming and development of the alpha-test prototype.

6) Writing the program documentation.

7) Internal evaluation.

8) Adjustments and development of the beta-test prototype.

9) External evaluation.

10)Adjustment and development of version 1.0.

Although the software development process seems linear, it is rather iterative; since the operation should be checked, and the results evaluated.

The initial idea is to create a tool based on the measurement of temperature, humidity and ph sensors. This idea creates the seed of WHAT (matter and level) for the realization of the work. The HOW (didactic strategy) was developed during the first design of the program.
For the pre-design, a script of the program was formed. Emphasis was placed on the pedagogical aspects of the project: content, objectives, teaching strategy, etc. For the development of the software, bibliographic sources were consulted as well as housewives and books dedicated to the care of plants and fruit trees, for example in [16].

Indications for plant care are provided through easy to understand diagrams; for example, for the preparation of the substrate is used in the Fig. 14.

The plant can communicate its "emotional" state by activating emoticons in animated gifs. See Table I. Showing an animated icon solves the problem of dealing with numbers or data that are strange to the end-user. Fig. 15 shows one of the generated screens; the interpreted state of the plant is observed by means of animation.

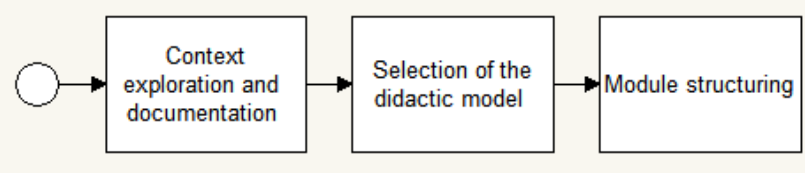

Fig. 13. Stages for Design.

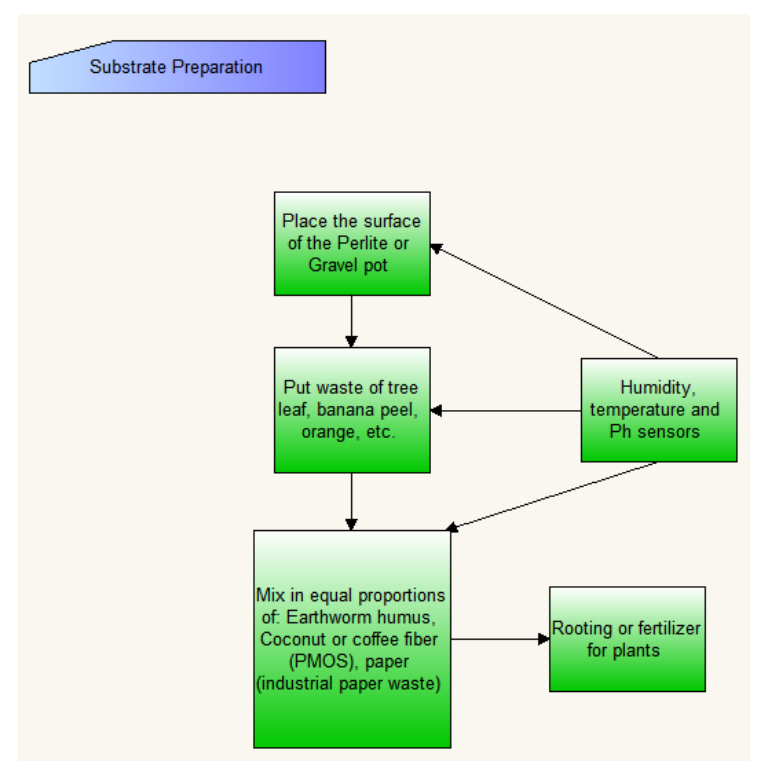

Fig. 14. Substrate Preparation.

TABLE. I. EMOTICONS VS STATE

\begin{tabular}{|l|l|l|}
\hline Emotion & State & Sensor \\
\hline 2 & Happiness & Humidity \\
\hline 6 & Anger & Temperature \\
\hline 2 & Sadness & Humidity \\
\hline & Fear & PH \\
\hline
\end{tabular}




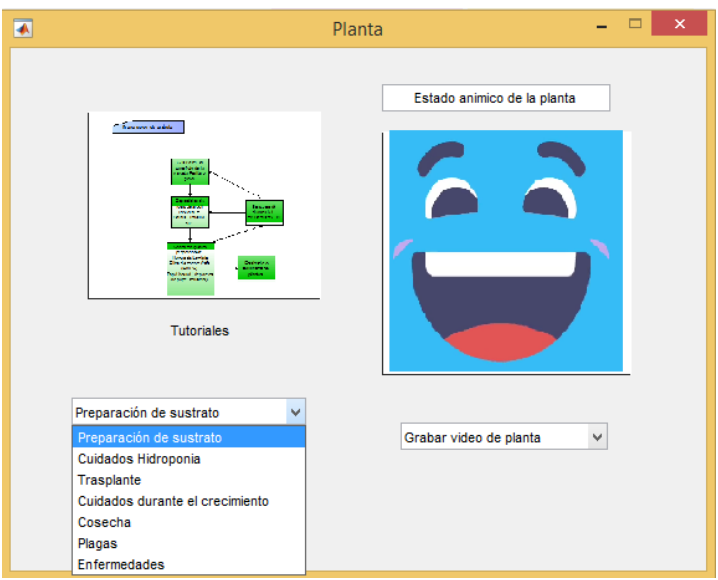

Fig. 15. Main Interface.

\section{RESUlts}

Plants were taken care of from planting to harvest. The system was tested for several days. He underwent continuous work for 2 months without interruption; Without presenting problems. The energy system is low consumption and does not work continuously since it depends on the atmospheric conditions, The energy system is low consumption and does not work continuously, since it depends on the atmospheric conditions, and is sufficient for the needs of the circuit. Wireless communication works properly within a $10 \mathrm{~m}$ radius. If you need more communication radius, you can use the internet.

The software tests performed are unitary. It was divided into modules to apply logical tests; that is, detection of learning styles, cognitive level and the proportion of educational resources.

The white box test cases are created from the selected units. For which input values were defined for the detection of learning styles and cognitive level. The proportion of educational resources is based on learning and cognition style.

As proof of usability, user interaction with the software was verified, to ensure that the interface provides navigation. The usability was made based on gender, location, age, and income level through questionnaires to a total of 65 people.

The graph in Fig. 16 shows that most people have a good opinion about the implementation of technology to assist their learning and awareness; Similarly, most respondents have used a mobile device such as laptops, tablets or smart-phone to search for information.

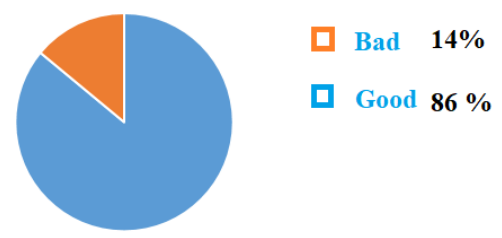

Fig. 16. The Opinion of the People Interviewed Regarding the use of Technology.
The graph in Fig. 17 shows that the majority $(67.7 \%)$ of respondents use an application to support their daily activities. Similarly, $56.9 \%$ agree that a mobile application can help them improve their performance.

Some of the reasons why users used the application are:

- Difficulty in understanding the care of plants.

- They consider that it helps to understand more easily.

- Facilitates the development of the solution to the problem.

Finally, $87.7 \%$ of the interviewees consider that if they were provided with a resource for the care of plants, they would benefit from the care of nature and obtain an economic income.

As for the plants with which the experiment was performed, the results shown in Table II were obtained. From the vegetables, lucrative crops of 10 lettuces have been obtained on average per house room, one per seed. Estevia harvest of 20 plants on average, and generation 3 plants of bell pepper. In watermelon, there are problems for the survival of the plant, as it requires special conditions. The strawberry requires more care, does not exceed a transplant. Notorious success stories were cilantro, onion, pumpkin, and tomato.

Pests have been successfully fought for tomato. Thus, slugs, aphids, and ants have been fought successfully. Fig. 18 shows the system for the case of stevia, where it was decided to leave the plants inside the fish tank to protect them and create an ecosystem.

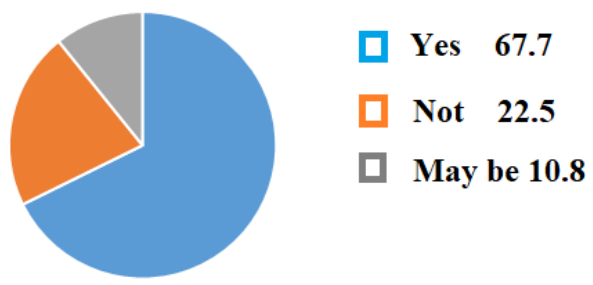

Fig. 17. People who use Applications to Rely on their Activities.

TABLE. II. EMOTICONS VS STATE

\begin{tabular}{|l|l|l|}
\hline Plant & Crecimiento & Cosecha \\
\hline Watermelon & $30 \mathrm{~cm}$ & Not harvested \\
\hline Stevia & $1.5 \mathrm{~m}$ & $\begin{array}{l}\text { It yields 1 liter per } \\
\text { plant. 20 Harvest }\end{array}$ \\
\hline Coriander & $10 \mathrm{~cm}$ & Harvested \\
\hline Strawberry & Germ & Not harvested \\
\hline Pumpkins & $20 \mathrm{~m}$ & $\begin{array}{l}10 \text { Pumpkins diameter } \\
60 \text { cm }\end{array}$ \\
\hline Tomato & $147 \mathrm{~cm}$ & $\begin{array}{l}\text { From fruits per week } \\
\text { were harvested }\end{array}$ \\
\hline Onion & $20 \mathrm{~cm}$ & One per seed \\
\hline Lettuce & $10 \mathrm{Cm}$ & 50 Peppers of 3 plants \\
\hline Pepper & $80 \mathrm{~cm}$ & \\
\hline
\end{tabular}




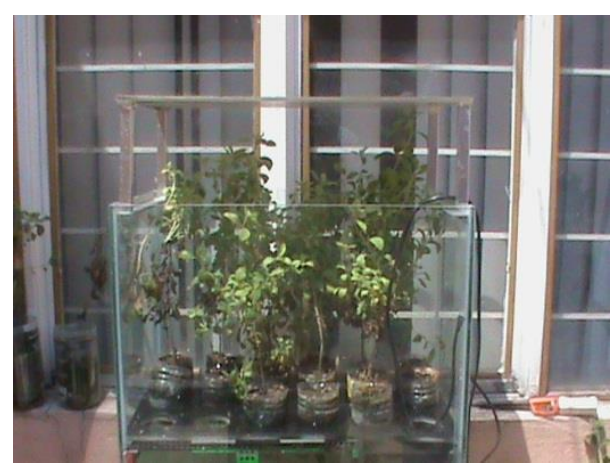

Fig. 18. Fish Tank for Hydroponics. Stevia Plant.

\section{CONCLUSIONS}

The tests carried out showed the autonomy of the system; since it can work 24 hours a day without setback. There is no problem in wireless communication, nor with the detection of the different measurements. It is feasible to implement the system with another microprocessor, although the Arduino system provides a method of easy implementation and economical. Flowcharts are useful if you need to use another embedded system.

The costs for both the hydroponic system are really low compared to the benefits. An even feasible product was obtained from being commercialized and a cultivation system for cities that can satisfy food needs in a short time, due to the success in production.

People, in general, have a good opinion regarding the use of computer technology as a support for learning and caring for plants.

If we consider the existing population in the cities, we can think that the software can reach a large number of people and therefore of possible users; which according to respondents can benefit and improve plant production. All expressed feeling great affection for nature after the use of the application and the harvest obtained.

In the area of affective computation, it allows expanding knowledge in the area of Life Sciences, generating an effective interaction with the plant.

\section{FUTURE WORK}

Develop an embedded system and affective or emotional software for the care of dwarf trees.

\section{ACKNOWLEDGMENT}

The authors thank the National Polytechnic Institute for the support received.

\section{REFERENCES}

[1] Resh, Howard M.Cultivos hidropónicos: nuevas técnicas de producción: una guía completa de los métodos actuales de cultivo sin suelo para técnicos y agricultores profesionales, así como para los aficionados especializados. No. 631.585. Mundi-Prensa,, 1997.

[2] J. D. Becerra-Barón and N. Y. Torres-Merchán, "El diseño de material didáctico como aporte al abordaje de los problemas ambientales en entornos educativos y comunitarios," Revista Educación, vol. 38, (2), pp. 1, 2014.

[3] M. Cebrián-de-la-Serna and J. Noguera-Valdemar, "Conocimiento indígena sobre el medio ambiente y diseño de materiales educativos," Comunicar, vol. 17, (34), pp. 115-124, 2010;2009.

[4] A. Molina, "Ensenara pirinola a cuidar los árboles," El Norte, 2005.

[5] J. P. Chacón et al, "Los contenidos curriculares digitalizados: Voces y silencios en el ámbito editorial/ The digitized curriculum: voices and silences in the publishing field," Educatio Siglo XXI, vol. 33, (3), pp. 39,2015 .

[6] Hezkuntza, L.. Huertos Escolares. Editorial CEIDA, Centro de educación e investigación didáctica ambiental, España., 1998.

[7] F. Lescourret et al, "QualiTree, a virtual fruit tree to study the management of fruit quality. I. Model development," Trees, vol. 25, (3), pp. 519-530, 2011.

[8] Dávila Sanabria, D. T., Galvis Álvarez, A. C., \& Vivas Granados, R. Sitio web como estrategia de enseñanza en la educación para la sostenibilidad. Praxis \& Saber, 6(11), 115-138, 2015.

[9] Huterwal, G. O. "Hidroponía: cultivo de plantas sin tierra." (1956).

[10] Barbado, José Luis. Hidroponía; su empresa de cultivos en agua. No. 631.585 B228. Albatros, 2005.

[11] Baixauli Soria, C., and J. M. Aguilar Olivert."Cultivo sin suelo de hortalizas: aspectos prácticos y experiencias." No. C057. 013. Generalitat Valenciana, 2002.

[12] Rodríguez Delfín, Alfredo, et al.Manual práctico de hidroponía. No. 631.585 M294m. Lima, PE: Universidad Agraria La Molina, 2004.

[13] Pan, Tianhong, and Yi Zhu. "Getting Started with Arduino."Designing Embedded Systems with Arduino. Springer, Singapore, 2018. 3-16

[14] Valdéz, Jorge, Daniel Pandolfi, and Andrea Villagra. "Redes de sensores inteligentes para monitoreo de datos remotos."XIX Workshop de Investigadores en Ciencias de la Computación (WICC 2017, ITBA, Buenos Aires). 2017.

[15] Castro, Jorge R.Building a Home Security System with Arduino. Packt Publishing Ltd, 2015.

[16] Geoffrey R. Dixon Dixon et al, Horticulture: Plants for People and Places, Volume 1: Production Horticulture. (2014th ed.) 2014. DOI: 10.1007/978-94-017-8578-5. 